\title{
Avaliação da cobertura vegetal e uso da terra da bacia hidrográfica costeira do rio Portinho, Piauí.
}

\author{
Evaluation of vegetation cover and land use of coastal river basin Portinho, Piauí.
}

Sousa, R. S1

roneide_2@hotmail.com

\begin{abstract}
Resumo
$\mathrm{O}$ artigo tem por objetivo analisar a variação espaçotemporal da vegetação e do uso e cobertura da terra da bacia hidrográfica do rio Portinho-PI. Para realizar esta análise foi utilizado o cálculo do Índice de Vegetação por Diferença Normalizada ou NDVI, através das bandas 3 e 4, obtidas nas imagens de satélite Landsat-7 ETM (1999) e Landsat-8 OLI (2014), bem como foi realizado o mapeamento do uso através da classificação supervisionada o que permitiu identificar sete tipos de uso e cobertura, a citar dunas móveis $(3,27 \%)$, planície flúvio lacustre associada à vegetação pioneira $(1,39 \%)$, caatinga arbustiva $(18,47 \%)$, planície de inundação associado ao pasto $(38,95 \%)$, floresta ciliar de carnaúba/caatinga de várzea $(18,92 \%)$, solo exposto associado à agricultura irrigada $(13,57 \%)$ e área de agricultura com culturas tradicionais $(5,40 \%)$. Os mapeamentos obtidos evidenciam que a vegetação natural aparece concentrada nas partes mais baixas do relevo, na planície litorânea, o manguezal concentra-se próximo a foz do rio Igaraçu, o solo exposto associado à agricultura de irrigação concentra-se na área do projeto dos tabuleiros costeiros, cuja fonte hídrica do perímetro irrigado é feita através do rio Parnaíba (perene). Contudo a espacialização dos usos atuais da bacia hidrográfica do rio Portinho se torna de grande relevância para o entendimento da dinâmica da área.
\end{abstract}

Palavras-chave: Uso da terra, NDVI, Sensoriamento Remoto

\begin{abstract}
The article aims to analyze the spatial and temporal variation of the NDVI and the use and land cover the basin of Portinho-PI river. To perform the calculation NDVI, we used the bands 3 and 4 obtained in the Landsat-7 ETM satellite images (1999) and Landsat-8 OLI (2014) and was carried out mapping of use through the supervised classification which identified seven types of use and coverage, quote moving dunes $(3.27 \%)$, plain fluvial lacustrine associated with pioneer vegetation $(1.39 \%)$, shrub savanna (18.47\%), flood plain associated with pasture $(38.95 \%)$, riparian forest carnauba / lowland caatinga $(18.92 \%)$, exposed soil associated with irrigated agriculture (13.57\%) and agricultural area with cyclical crops $(5.40 \%)$. The obtained mapping shows that the natural vegetation appears concentrated in the lower parts of the relief on the coastal plain, the mangrove is concentrated near the mouth of the Igaraçu River, the exposed soil associated with irrigated agriculture is concentrated in the project area of the coastal plains whose water source irrigated perimeter is done by the river Parnaíba (perennial). However, the spatial distribution of current uses of basin Portinho river becomes highly relevant for understanding the dynamics of the area.
\end{abstract}

Keywords: Land use, NDVI, Remote Sensing

\section{INTRODUÇÃO}

Estudos acerca das bacias hidrográficas desempenham importante função na análise geomorfológica por se constituírem em unidades espaciais onde se processam, de forma integrada, as relações entre seus componentes. Esta característica possibilita configurá-las como uma unidade físico-territorial de planejamento (SANTOS et al, 2012). Para Gorayeb (2008) trata-se de uma unidade geográfica fundamental para o gerenciamento dos recursos hídricos e para o planejamento ambiental.

Para Guerra e Cunha (1999) o estudo de uma bacia hidrográfica implica no entendimento da sua forma na superfície terrestre, sendo que a mesma pode ser entendida como uma área da 
superfície que drena água, sedimentos e materiais para a saída comum, num determinado ponto do canal fluvial. Ainda conforme os autores, elas se configuram como uma unidade espacial fundamental no planejamento físico e ambiental, pois apresentam suas delimitações baseadas em critérios geomorfológicos, que são mais precisos devido a seus limites naturais. Assim, ao analisala, é importante que estabeleça um elo entre todos os componentes do sistema.

Compreender os fenômenos e processos que ocorrem em uma bacia hidrográfica, sob a perspectiva da teoria dos sistemas aplicada aos estudos geográficos (BERTRAND; BERTRAND, 2007), torna-se importante ao possibilitar a análise dos diversos elementos que a compõem, como a base geológica, dados de precipitação, unidades de relevo, solos, cobertura vegetal e escoamento superficial, bem como a ocupação e uso da terra e, assim, subsidiar propostas de planejamento para a gestão da bacia hidrográfica.

Dessa forma, a analise da cobertura vegetal é importante, pois ela possui grande participação na redução da erosão hídrica (CARDOSO et al., 2012). A cobertura vegetal auxilia na redução da erosão hídrica interceptando as gotas de chuva que impactariam diretamente a superfície do solo. E com o auxilio do sensoriamento remoto é possível à obtenção de dados da superfície terrestre, sendo este uma importante técnica para o monitoramento sistemático dinâmico da vegetação.

Os estudos voltados para compreensão dos diferentes aspectos que compõem as unidades paisagísticas recorrem à necessidade de se utilizar abordagens sistêmicas e integradas para análise do meio ambiente, contemplando aspectos voltados à relação entre a natureza e sociedade. Dessa forma, o artigo tem por objetivo analisar a variação espaço-temporal do NDVI e o uso e cobertura da terra da bacia hidrográfica do rio Portinho-PI.

\section{METODOLOGIA}

\subsection{Localização da área de estudo}

As bacias litorâneas piauienses constituem-se por um conjunto de pequenas bacias localizadas no extremo norte do estado, drenadas diretamente para o oceano, os principais rios dessas bacias são o rio Portinho, rio Camurupim, rio São Miguel e o rio Carpina.

Dessa forma, a bacia hidrográfica costeira a ser analisada é a bacia do rio Portinho, localizada no norte piauiense, com área e perímetro aproximado de $393 \mathrm{~km}^{2}$ e $153 \mathrm{~km}$, respectivamente (Figura 1). Sua foz vai de encontro ao tributário do rio Parnaíba, o rio Igaraçu, que posteriormente unem-se as águas do oceano Atlântico. A bacia hidrográfica compreende os municípios de Parnaíba, maior proporção, parte de Luís Correia, parte de Buriti dos Lopes e parte de Bom Principio do Piauí (BAPTISTA, 1975, FUNDAÇÃO CEPRO, 1984). 
O clima da área em estudo é classificado como do tipo Aw' - Clima Tropical Chuvoso, com temperatura do ar média de $26,7^{\circ} \mathrm{C}$ quente e úmido, segundo a classificação de Koppen. A precipitação média anual da região é da ordem de $1.153 \mathrm{~mm}$, com base nos dados da estação meteorológica do município de Parnaíba. A umidade relativa média anual é de aproximadamente $80 \%$ e a evaporação medial anual é de $1.750 \mathrm{~mm}$, e a evapotranspiração potencial é estimada em 1.557 mm (INMET, 2010, BASTOS, 2011).

Figura 1 - Localização da área de estudo
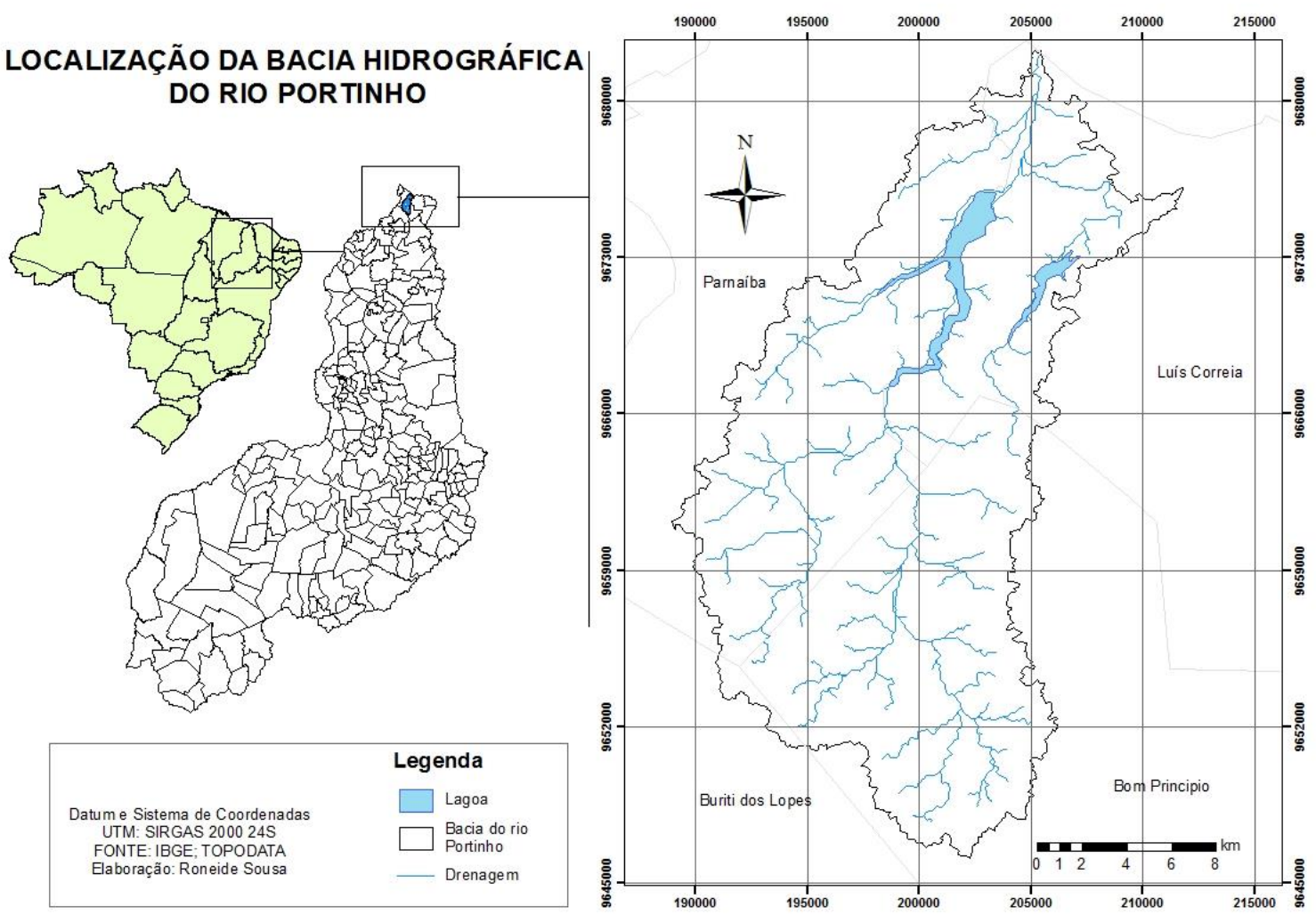

O período chuvoso inicia-se na segunda quinzena do mês de dezembro com chuvas de préestação e prolonga-se até o mês de maio, tendo os meses mais chuvosos de Janeiro a Abril. O déficit hídrico está condicionado no inicio de Agosto a Janeiro, particularmente durante os meses de temperaturas mais elevadas, época em que ocorre maior retirada de água do solo, superando desta forma o excedente hídrico (BASTOS, 2011).

O contexto geológico e geomorfológico da bacia hidrográfica do rio Portinho engloba sedimentos das Formações Superficiais Continentais, representados pelo Grupo Barreiras de idade plio-pleistocênica e pelas Coberturas Pleistocênicas e Holocênicas do Quaternário, representados pelos depósitos eólicos litorâneos, depósitos de pântanos e mangues atuais, depósitos de terraços e cordões litorâneos, e depósitos flúvio lacustres (RADAMBRASIL, 1981, AGUIAR, 2004). 
Os depósitos de pântanos e mangues englobam areia e argila e também fazem parte dos sedimentos recentes. O Grupo Barreiras agrupa arenito, conglomerado, intercalações de siltito e argilito. Na porção basal encontram-se os sedimentos do Grupo Serra Grande constituído de conglomerado, arenito e intercalações de siltito e folhelho. $\mathrm{O}$ embasamento cristalino é representado pelo Complexo Granja, composto de gnaisse que apresentam características litológicas que variam em função do ambiente em que foram depositados os sedimentos (RADAMBRASIL, 1981, AGUIAR, 2004).

Os principais tipos de solos identificados foram: Argissolo Vermelho-Amarelo Distrófico e Álico, Argissolo Vermelho-Amarelo Álico, Espodossolo Ferrihumilúvico Hidromórfico, Neossolo Quartzarênico, Plintossolo e Solo Indiscriminado de Mangue. Na área de estudo, o Argissolo Vermelho-Amarelo Distrófico constitui a classe dominante nos Tabuleiros Costeiros, ocorrendo quase sempre em associação com outros componentes, principalmente o Latossolo Amarelo Distrófico e, secundariamente com o Neossolo Quartzarênico Órtico. De forma subordinada ocorre o Argissolo Amarelo Distrófico (JACOMINE, 1986).

\subsection{Procedimentos metodológicos}

\subsubsection{Análise da cobertura vegetal através do NDVI}

Para a geração do índice de vegetação por diferença normalizada (NDVI), sendo este expresso pela razão entre a diferença da média da reflectância do infravermelho próximo (NIR) e do vermelho $(\mathrm{R})$ e a soma dos mesmos canais, tendo-se assim a expressão:

$$
\mathrm{NDVI}=(\mathrm{NIR}-\mathrm{R}) /(\mathrm{NIR}+\mathrm{R})
$$

onde:

NDVI = Índice de Vegetação por Diferença Normalizada

NIR = banda do infravermelho próximo

$\mathrm{R}=$ banda do vermelho

Foram utilizadas as bandas dos sensores Landsat-7 ETM para o ano de 1999 (02/08/1999) e Landsat-8 OLI, para o ano de 2014 (09/10/2015), e manipuladas através da calculadora raster através do software ArcGIS10.1. Dessa forma, o produto do NDVI pode determinar as propriedades espectrais da vegetação, onde o cálculo do índice é feito a partir da diferença entre as refletâncias das bandas 4 (infravermelho próximo) e 3 (visível-vermelho) dividido pela soma das refletâncias dessas duas bandas. O resultado da combinação varia de -1 a 1 , de modo que quanto mais próximo do 1 , maior indício de presença de vegetação, e quanto mais próximo do -1 , maior indício de presença de solo exposto. 


\subsubsection{Uso e Cobertura da terra}

A metodologia consistiu na utilização de imagens de satélites, Landsat-8 OLI para o ano de 2014, obtidas no site da NASA (glovis.usgs.gov), além de dados topográficos extraídos da base STRM, do banco de dados da TOPODATA e CPRM (2009).

A primeira etapa metodológica consistiu no recorte da bacia representativa da área de estudo, levando em consideração o rio principal o Portinho. Em seguida, foram realizadas as etapas de definição dos alvos de interesse e posterior classificação das imagens pelo método supervisionado pelo algoritmo de Máxima Verossimilhança (MAXVER).

Para a área ainda foram realizadas as etapas de calibração, correção atmosférica e normalização radiométrica, com o intuito de minimizar características que não pertencem aos alvos das cenas imageadas (ruídos do sensor, atmosfera, nuvens etc.) e tornar as imagens multitemporais radiometricamente comparáveis entre si (PONZONI ET AL., 2007).

O princípio de classificação supervisionada é baseado no uso de algoritmos para se determinar os pixels que representam valores de reflectância característicos para uma determinada classe. A classificação supervisionada é a mais utilizada na análise quantitativa dos dados de sensoriamento remoto (JENSEN, 2007, FLORENZANO, 2008). As validações das classes de usos após imagem classificada, utilizou-se a estatística Kappa para testar a concordância entre os resultados observados e os classificados em uma tabela de contigência (matriz de erro).

\section{RESULTADOS E DISCUSSÃO}

\subsection{Avaliação da cobertura Vegetal}

A análise da cobertura vegetal foi realizada através do Índice de Vegetação da Diferença Normalizada (NDVI), sendo este um índice que permite identificar a presença de vegetação verde na superfície e caracterizar sua distribuição espacial, como também identificar sua evolução no decorrer do tempo.

Nos mapas que seguem observa-se que a refletância na área em estudo para o ano de 1999, variou entre os valores de $-0,3$ a 0,57 e para o ano de 2014 , variou de $-0,1$ e 0,58 . A figura 1 representa a espacialização do Índice de Vegetação da Diferença Normalizada para a área de estudo. 

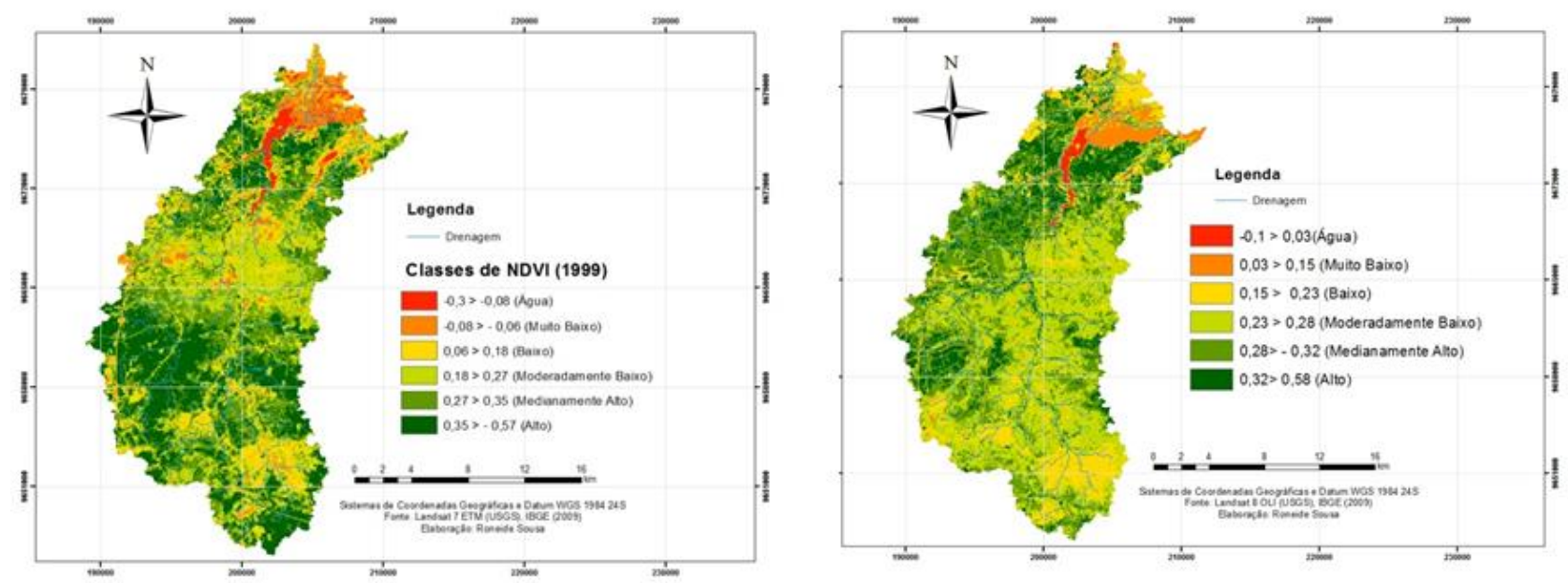

Figura 1 -NDVI para a bacia hidrográfica do rio Portinho para o ano de 1999 e 2014

Observa-se que houve variação do comportamento da vegetação entre os anos de 1999 e 2014. Com uma redução significativa de corpos hídricos na área de estudo, nas proximidades da lagoa do Portinho e lagoa adjacente. As classes correspondentes ao nível muito baixo e baixo representam áreas de dunas móveis e áreas de planícies de deflação eólica respectivamente. Na figura 2, em seguida, pode-se observar através do gráfico a variação da cobertura vegetal para os anos de 1999 e 2014.

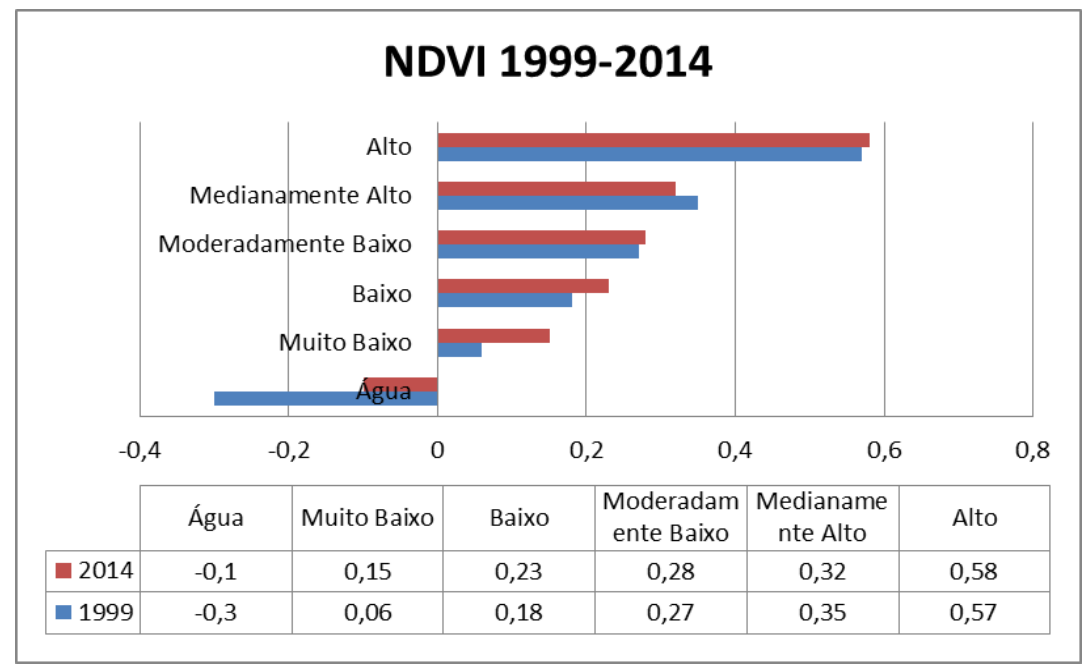

Figura 2- Variação do NDVI para os anos de 1999-2014

Destaca-se na porção sul da bacia a diminuição da cobertura vegetal natural, devido à implantação do projeto do perímetro irrigado tabuleiros litorâneos do Piauí, que teve sua efetivação a partir de 1998, conforme o Departamento Nacional de Obras Contra as Secas - DNOCS. Embora, na análise do gráfico mostre que a área verde teve um aumento de 0,1 , na classe Alta, este vem a representar os cultivos dentro do perímetro irrigado. Na área em questão destaca-se principalmente o cultivo de banana, coco, milho verde e do feijão. Tabela 1. 
Tabela 1. Características do projeto de Irrigação dos Tabuleiros Litorâneos em Parnaíba

\begin{tabular}{cc}
\hline Área Total Desapropriada & ÁREA (ha) \\
\hline Área de Sequeiro & $1.026,65$ \\
Área Irrigável & $8.007,00$ \\
A ser implantado & $5.538,00$ \\
Implantada & $2.469,00$ \\
Com Produtor & $2.273,00$ \\
\hline
\end{tabular}

Fonte: DNOCS, 2012

\subsection{Uso e cobertura da terra}

O mapeamento do uso e cobertura da terra foi realizado através da classificação supervisionada, o que permitiu identificar sete tipos de uso para a bacia hidrográfica do rio Portinho, a citar dunas móveis, planície flúvio lacustre associada à vegetação pioneira, vegetação de caatinga arbustiva, planície de inundação associado a pasto, floresta ciliar de carnaúba/caatinga de várzea, solo exposto associado à agricultura irrigada e área de agricultura com culturas mista, conforme pode ser visto na figura 3 e no Quadro 1.

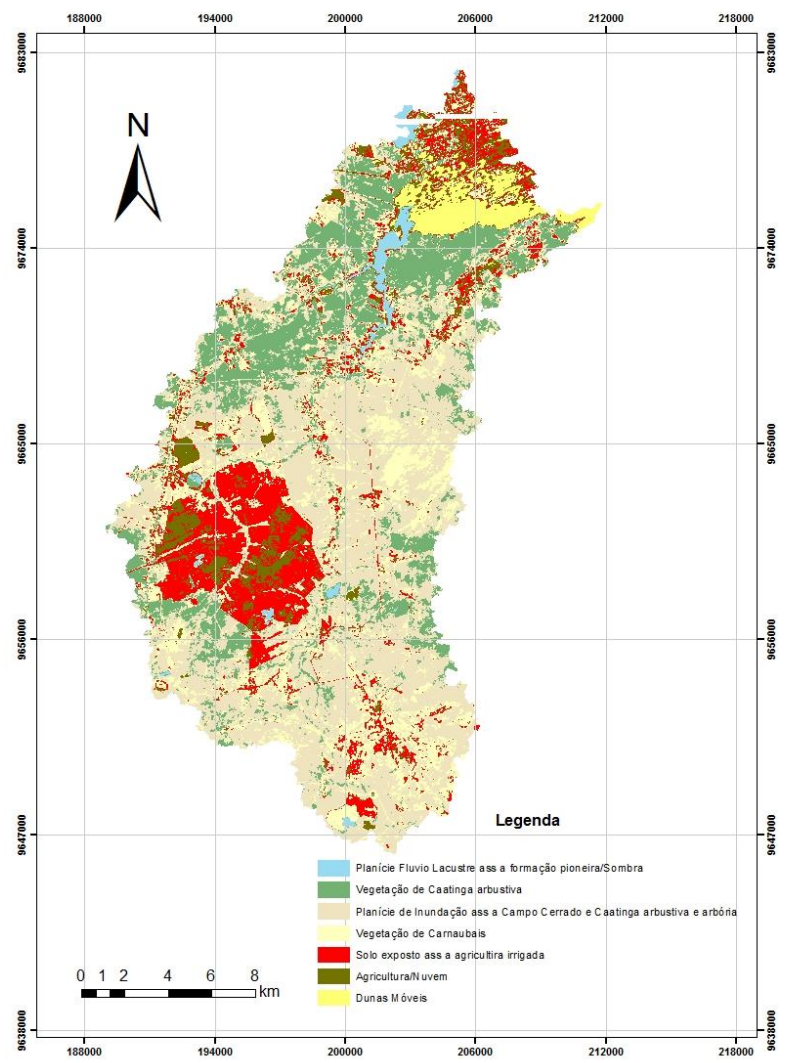

Figura 3 - Uso e cobertura da terra da bacia hidrográfica do rio Portinho 
Quadro 1. Classes de uso e cobertura da terra

\begin{tabular}{|l|l|l|}
\hline \multicolumn{1}{|c|}{ Uso da terra } & Área $(\mathbf{k m})$ & \multicolumn{1}{c|}{$\%$} \\
\hline Planície flúvio lacustre ass a vegetação pioneira & 5,46 & 1,39 \\
\hline Vegetação de caatinga arbustiva & 72,46 & 18,47 \\
\hline Planície de Inundação associada a pasto & 152,81 & 38,95 \\
\hline Floresta ciliar de carnaúbas/caatinga de várzea & 74,24 & 18,92 \\
\hline Solo exposto associado à agricultura irrigada & 53,23 & 13,57 \\
\hline Agricultura com culturas mistas & 21,20 & 5,40 \\
\hline Dunas Móveis & 12,86 & 3,27 \\
\hline
\end{tabular}

O mapa de uso e cobertura da terra obtida mostra que na bacia hidrográfica em estudo há predomínio de áreas de pastagem, representada pela área de planície de inundação associado a campo cerrado e caatinga arbustiva, seguido pela vegetação de Carnaúbas associada à agricultura mista, ocupando, respectivamente, $38,95 \%$ e $18,47 \%$ da sua área total.

A vegetação natural aparece concentrada nas partes mais baixas do relevo na planície litorânea. O manguezal concentra-se na foz do rio Igaraçu, onde se concentra em uma pequena área da bacia. Na figura 4 observa-se a diversidade de paisagem na área de estudo.
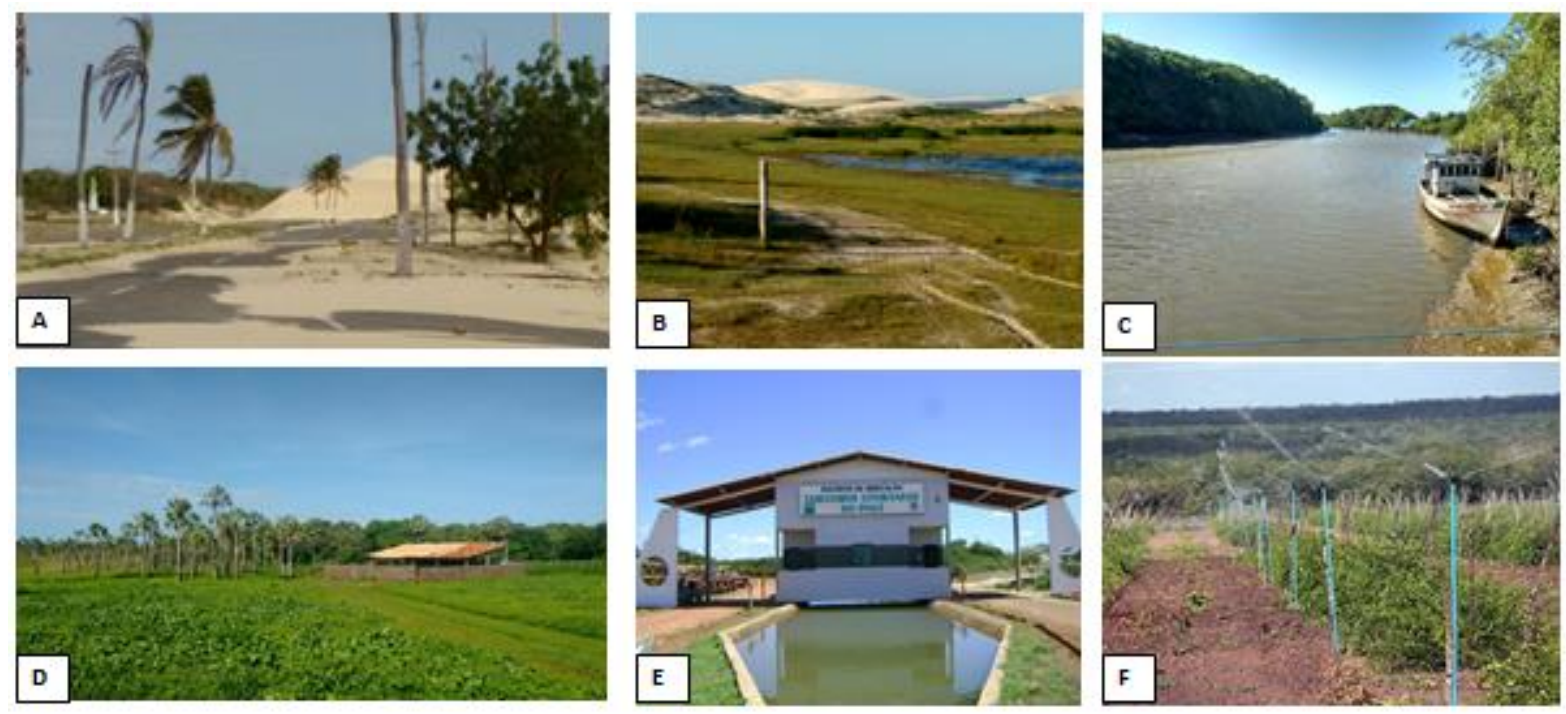

Figura 4. A: Migração de Dunas móveis sob a estrada que dar acesso a lagoa do Portinho; B: espelhos d'agua da planície flúvio-lacustre do rio Portinho, ao fundo dunas móveis em Parnaíba; C: Manguezal na proximidade da foz do rio Igaraçu-Luís Correia; D: Planície de inundação associada a vegetação de carnaúbas, em Bom Princípio do Piauí; E: Entrada do projeto perímetro irrigado dos tabuleiros litorâneos em Parnaíba; F: Perímetro Irrigado com foco no cultivo de frutas (acerola, caju, coco, goiaba, melão, melancia) e feijão. Fonte: Sousa e Thiago Amaral (foto F). 
Observa-se na área a migração das dunas móveis sob o asfalto, sendo uma das principais vias de acesso para a lagoa do portinho. Esta que é considerada um dos pontos turísticos do município de Parnaíba, com estruturas construídas para receber visitantes, a mesma devido à estiagem, o barramento de suas águas e a migração natural das dunas, teve seu corpo hídrico comprometido. Atualmente a lagoa passou por intervenção público/particular que permitiu que a mesma tivesse seu potencial hídrico parcialmente restabelecido.

O solo exposto associado à agricultura de irrigação concentra-se na área do projeto dos tabuleiros costeiros, cuja fonte hídrica do perímetro irrigado é feita através do Rio Parnaíba (perene). Ainda, no mapa de uso e cobertura evidencia-se a área do perímetro irrigado, apresentando uma variação no comportamento da área verde, devido à produção das diferentes culturas.

\section{CONSIDERAÇÕES FINAIS}

A análise da cobertura vegetal por meio do índice de vegetação NDVI, se mostrou eficiente na avaliação da cobertura vegetal para a bacia do rio Portinho, ao passo que a mesma pôde evidenciar mudanças no comportamento da vegetação durante os anos de 1999 e 2014. Pode-se notar uma diminuição do corpo hídrico e um aumento significativo da perda da cobertura vegetal natural, após a instalação do perímetro irrigado ao sul da bacia hidrográfica, este que compreende os municípios de Parnaíba e Buriti dos Lopes.

A partir da classificação supervisionada de imagens do satélite Landsat OLI-8 do ano de 2014, foi possível mapear as principais classes de usos da bacia hidrográfica do rio Portinho, contribuindo com o melhor conhecimento da área de estudo, localizada na planície costeira piauiense, bem como permitiu uma análise dos processos naturais a antrópicos que têm contribuído com a alteração das paisagens existentes na bacia.

O sensoriamento remoto se mostrou como uma ferramenta eficaz na obtenção de dados da superfície terrestre, que constituí uma importante técnica para o monitoramento sistemático dinâmico da vegetação.

Contudo, não foi objetivo esgotar a análise na presente bacia, esta que vem sofrendo com variações de corpos d'águas, migrações dunares, mudanças climáticas e principalmente as alterações antrópicas, esta pesquisa busca somar e contribuir ao planejamento ambiental da área, bem como incentivar pesquisas na mesma. 


\section{REFERÊNCIAS}

AGUIAR, R. B. de. Projeto cadastro de fontes de abastecimento por água subterrânea, estado do Piauí: diagnóstico do município de Parnaíba / Organização do texto [por] Robério Bôto de Aguiar [e] José Roberto de Carvalho Gomes . Fortaleza: CPRM - Serviço Geológico do Brasil, 2004.

BASTOS, E. A. 2011. Boletim agrometeorológico de 2010 para o município da Parnaíba, Piauí. Teresina, Embrapa Meio-Norte. 32p.

BERTRAND, G.; BERTRAND, C. Uma geografia transversal e de travessias: o meio ambiente através dos territórios e das temporalidades. Maringá: Massoni, 2007.

CARDOSO, D. P.; SilvA, M. L. N.; CARVAlHO, G. J.; FREITAS, D. A. F.; AVANZI, J. C. Plantas de Cobertura no Controle das Perdas de Solo, Água e Nutrientes por Erosão Hídrica. Revista Brasileira de Engenharia Agrícola e Ambiental, Campina Grande, v. 16, p. 632-638, 2012. http://dx.doi.org/10.1590/S1415-43662012000600007.

FUNDAÇÃO CEPRO. Macrozoneamento Costeiro do Estado do Piauí: Relatório Geoambiental e Socioeconômico. Teresina: s.e, 1996. 221p. ilust.1984.

Florenzano, T. G. 2008. Sensoriamento Remoto para geomorfologia. Geomorfologia: conceitos e tecnologias atuais. São Paulo: Oficina de Textos:12-35.

GORAYEB, A. Análise Integrada da Paisagem na Bacia Hidrográfica do rio Caeté -Amazônia Oriental-Brasil. Rio Claro: UNESP, Programa de Pós-Graduação em Geografia. Tese de Doutorado. 2008.

GUERRA, A.J.T; CUNHA, S.B. Geomorfologia: uma atualização de bases e conceitos. 2. ed. São Paulo: Bertrand Brasil, 1999. 98p.

JACOMINE, P.K.T. - Levantamento exploratório-reconhecimento de solos do estado do Piauí. Recife: DPP, AgMA/DNPEA, SUDENE/DRN, $1^{\circ}$ Vol., Boletim de pesquisa nº 26, 1986. 383 p JENSEN, J. R. 2007. Remote sensing of the environment: an earth resource perspective: Pearson Prentice Hall.

PONZONI, F.J.; ZULLO JUNIOR, J.; LAMPARELLI, R.A.C. Calibração absoluta de sensores orbitais: conceituação principais procedimentos e aplicação. São José dos Campos, SP: Ed. Parêntese, 65p., 2007.

RADAMBRASIL. Levantamento de Recursos Naturais, 21-23. Instituto Brasileiro de Geografia e Estatística. Rio de Janeiro, 1981.

SANTOS, L. A; SOUSA, T.M; LIMA, A. S; LIMA, I. M. M. F. Bacia hidrográfica do rio guaribas, Piauí: Aspectos da geomorfologia fluvial. Simpósio Nacional de Geomorfologia - SINAGEO, 2012, Rio de Janeiro. Anais IX Simpósio Nacional de Geomorfologia, 9. 2012. Anais. Rio de Janeiro. Rio de Janeiro: União da Geomorfologia Brasileira, 2012.

Recebido em: 14/08/2016

Aceito para publicação em: 01/10/2016 